\title{
JNPH
}

Volume 6 No. 2 (Oktober 2018)

(C) The Author(s) 2018

\section{HUBUNGAN KARAKTERISTIK DAN DUKUNGAN SUAMI DENGAN SELF EFFICACY MENYUSUI DALAM MEMBERIKAN ASI EKSLUSIF PADA BAYI DI RUMAH SAKIT DR. SOBIRIN KAB. MUSI RAWAS TAHUN 2018}

\section{THE RELATIONSHIP BETWEEN HUSBAND'S CHARACTERISTICS AND SUPPORT WITH BREASTFEEDING SELF-EFFICACY IN DELIVERING EXCLUSIVE BREASTFEEDING TO INFANTS AT DR. SOBIRIN HOSPITAL IN MUSI RAWAS REGENCY IN 2018}

\author{
SITI AMINAH, IDA SAMIDAH, MIRAWATI, DELTA APRIANTI \\ JL, MERAPI RAYA NO. 43 KEBUN TEBENG BENGKULU TELP. (0736) 21977
}

\begin{abstract}
ABSTRAK
Secara statistik sekitar 3\% balita tidak dapat mencapai perkembangan motorik mereka tepat waktu. Namun dari jumlah itu, hanya sekitar $15-20 \%$ anak-anak mengalami perkembangan abnormal, sedangkan sisanya masih bisa berkembang normal meski sedikit lebih lambat. Tujuan penelitian ini adalah untuk mengetahui hubungan antara pola asuh dengan perkembangan anak usia 4-6 tahun di Puskesmas Muara Kulam di Kecamatan Ulu Rawas tahun 2018. Penelitian ini merupakan penelitian analitik dengan menggunakan desain cross-sectional. Populasi dalam penelitian ini adalah semua anak usia 4-6 tahun di Puskesmas Muara Kulam di Kecamatan Ulu Rawas pada tahun 2018 yang berjumlah 135 anak, dengan total sampel sebanyak 58 responden diambil dengan teknik accidental sampling. Hasil analisis univariat menunjukkan bahwa sebagian kecil responden $(24,1 \%)$, memiliki perkembangan yang tidak dapat diuji, hampir separuh dari responden $(39,7 \%)$, tidak memiliki pola asuh dan analisis bivariat yang baik menunjukkan bahwa ada hubungan asuh dengan perkembangan anak usia 46 tahun di Puskesmas Muara Kulam di Ulu Rawas Tahun 2018 ( $\mathrm{p}=0,001$. Kepada pihak Puskesmas diharapkan berperan dalam mendeteksi perkembangan anak usia dini secara optimal dan memberikan pemahaman kepada orang tua dalam perkembangan anak-anaknya.
\end{abstract}

Kata kunci: Pengasuhan, Pengembangan Anak

\begin{abstract}
Statistically around 3\% of toddlers cannot reach their motoric development on time. But from that number, only about $15-20 \%$ of children have abnormal development, while the rest can still develop normally even though a little slower. The aim of this study is to determine the relationship between parenting with the development of children aged 4-6 years at Muara Kulam health centre in Ulu Rawas sub-district in 2018. This research is an analytic research using cross-sectional design. The population in this study were all children aged 4-6 years in Muara Kulam Public Health Centre in Ulu Rawas Sub-district in 2018 which amounted to 135 children, with a total sample of 58 respondents taken by accidental sampling technique. The results of univariate analysis showed that a small proportion of respondents $(24.1 \%)$, had untestable development, almost half of the respondents (39.7\%), had not a good parenting and
\end{abstract}


bivariate analysis showed that there was a relationship parenting with the development of children aged 4-6 years at Muara Kulam health centre in Ulu Rawas 2018 ( $p=0.001$. To the health centre is expected to play a role in detecting early child development optimally and providing understanding to parents in the development of their children.

\section{Keywords: Parenting, Child Development}

\section{PENDAHULUAN}

Untuk meningkatkan angka pencapaian pemberian ASI ekslusif diperlukan dukungan suami dan self efficacy yang tinggi dari ibu menyusui itu sendiri, karena suami adalah orang terdekat ibu yang banyak berperan selama kehamilan, persalinan dan setelah bayi lahir, termasuk pemberian ASI. Dukungan suami yang diberikan dalam bentuk apapun, dapat mempengaruhi kondisi emosional ibu yang berdampak terhadap produksi ASI (Ramadani dan Hadi, 2010). Rasa percaya diri ibu untuk menyusui adalah bahwa ibu mampu menyusui dengan produksi ASI yang cukup untuk bayi. Self efficacy menyusui menjadi salah satu faktor penting yang mempengaruhi pemberian ASI (Mulyati S \&Waluyanti FT, 2013).

Hasil wawancara yang peneliti lakukan pada 7 orang pasien di RS Dr. Sobirin, diketahui 5 orang memiliki tingkat pengetahuan baik, 2 orang memiliki tingkat pengetahuan kurang, sedangkan 3 orang mengatakan mendapat dukungan suami dalam menyusui, 4 orang mengatakan tidak mendapat dukungan suami, dan 5 orang mempunyai tingkat self efficacy tinggi, 2 orang mempunyai tingkat self efficacy rendah.

\section{METODE PENELITIAN}

Teknik pengumpulan data dalam penelitian ini dengan menggunakan data primer dan data sekunder. Data primer adalah data yang dikumpulkan dengan membagikan kuisioner langsung pada responden, Sedangkan data sekunder adalah data yang diperoleh dari laporan tahunan RS Dr. Sobirin Kab. Musi Rawas.

\section{HASIL PENELITIAN}

Analisis univariat pada penelitian ini untuk melihat distribusi frekuensi karakteristik ibu menyusui dan dukungan suami, serta variabel dependen yaitu self efficacy ibu. Analsis bivariate pada peneltian ini untuk melihat hubungan karakteristik ibu menyusui dan dukungan suami dengan self efficacy ibu. Selengkapnya hasil analisis univariat dan bivariate disajikan dalam tabel sebagai berikut :

Tabel 1. Distribusi Frekwensi Berdasarkan Karakteristik Ibu Menyusui (Umur, Pendidikan, Pekerjaan, Parietas dan Pengetahuan) di RS Dr. Sobirin Kab. Musi Rawas Tahun 2018

\begin{tabular}{|c|c|c|}
\hline Karakteristik Ibu & $\mathbf{n}$ & $\%$ \\
\hline \multicolumn{3}{|l|}{ Umur } \\
\hline$<20$ & 7 & 12,1 \\
\hline $20-30$ & 37 & 63,8 \\
\hline $31-45$ & 14 & 24,1 \\
\hline Total & 58 & 100 \\
\hline \multicolumn{3}{|l|}{ Pendidikan } \\
\hline Dasar (SD) & 7 & 12,1 \\
\hline Menengah (SLTP, & 46 & 79,3 \\
\hline SLTA) & 5 & 8,6 \\
\hline \multicolumn{3}{|l|}{ Tinggi (S1) } \\
\hline Total & 58 & 100 \\
\hline \multicolumn{3}{|l|}{ Pekerjaan } \\
\hline IRT & 23 & 37,9 \\
\hline PNS & 10 & 17,2 \\
\hline Swasta & 25 & 43,1 \\
\hline Total & 58 & 100 \\
\hline \multicolumn{3}{|l|}{ Parietas } \\
\hline Parietas 1 & 14 & 24,1 \\
\hline Parietas 2 & 33 & 56,9 \\
\hline Parietas 3 & 11 & 19,0 \\
\hline Total & 58 & 100 \\
\hline \multicolumn{3}{|l|}{ Pengetahuan } \\
\hline Baik & 46 & 79,3 \\
\hline Kurang & 12 & 20,7 \\
\hline
\end{tabular}




\begin{tabular}{ccc}
\hline Total & 58 & 100 \\
\hline
\end{tabular}
bahwa :

Dari tabel di atas dapat diketahui

1) Sebagian kecil dari responden $(12,1 \%)$ berumur $<20$ tahun, lebih dari sebagian responden $(63,8 \%)$ berumur 20-30 tahun, sebagian kecil responden (24,1\%) berumur 31-45 tahun.

2) Sebagian kecil dari responden $(12,1 \%)$ berpendidikan Dasar (SD), lebih dari sebagian responden (79,3\%) berpendidikan Menengah (SLTP, SLTA), sebagian kecil responden $(8,6 \%)$ berpendidikan Tinggi (S1).

3) Sebagian kecil dari responden (37,9\%) dengan pekerjaan IRT, sebagian kecil dariresponden $(17,2 \%)$ dengan pekerjaan PNS, Sebagian kecil dari responden $(24,1 \%)$ dengan pekerjaan Swasta.

4) Sebagian kecil dari responden $(24,1 \%)$ dengan parietas 1 , lebih dari sebagian responden $(56,9 \%)$ dengan parietas 2 , sebagian kecil dari responden (19\%) dengan parietas 3 .

5) Sebagian besar dari responden (79,3\%) memiliki tingkat pengetahuan baik, sebagian kecil dari responden (20,7\%) memiliki tingkat pengetahuan kurang.

Tabel 2. Distribusi Frekwensi Berdasarkan Dukungan Suami Ibu Menyusui di RS Dr. Sobirin Kab. Musi Rawas Tahun 2018

\begin{tabular}{ccc}
\hline Dukungan Suami & $\mathbf{N}$ & $\mathbf{\%}$ \\
\hline Baik & 41 & 70,7 \\
Kurang & 17 & 29,3 \\
\hline Total & 58 & 100 \\
\hline
\end{tabular}

Dari tabel di atas dapat diketahui bahwa lebih dari sebagian responden $(70,7 \%)$ memiliki dukungan suami baik dan sebagian kecil dari responden $(29,3 \%)$ memiliki dukungan suami kurang.

Tabel 3. Distribusi Frekwensi Berdasarkan Self Efficacy Ibu Menyusui Dalam Memberikan ASI Eksklusif di RS Sobirin

\section{Tahun 2018}

\begin{tabular}{ccc}
\hline Self Efficacy & $\mathbf{N}$ & $\mathbf{\%}$ \\
\hline Baik & 51 & 87,9 \\
Kurang & 7 & 12,1 \\
\hline Total & 58 & 100 \\
\hline
\end{tabular}

Dari tabel di atas dapat diketahui bahwa sebagian besar dari responden $(87,9 \%)$ memiliki self efficacy baik dan sebagian kecil dari responden (12,1\%) memiliki self efficacy kurang.

Tabel 4. Hasil Uji Hubungan Antara Variabel Karakteristik Ibu Dengan Self Efficacy Ibu Menyusui Dalam Memberikan ASI Eksklusif Pada Bayi di RS Sobirin Tahun 2018

\begin{tabular}{|c|c|c|c|c|c|c|c|}
\hline \multirow{3}{*}{$\begin{array}{c}\text { Karakteristik } \\
\text { Ibu }\end{array}$} & \multicolumn{4}{|c|}{ Self Efficacy } & \multirow{2}{*}{\multicolumn{2}{|c|}{ - Jumlah }} & \multirow{3}{*}{$\boldsymbol{P}$} \\
\hline & \multicolumn{2}{|c|}{ Baik } & \multicolumn{2}{|c|}{ Kurang } & & & \\
\hline & 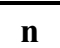 & $\%$ & $\mathbf{n}$ & $\%$ & $\mathbf{N}$ & $\%$ & \\
\hline \multicolumn{7}{|l|}{ Umur } & \multirow{4}{*}{0,20} \\
\hline$<20$ & 4 & 7,8 & 3 & 42,9 & 7 & 12,1 & \\
\hline $20-30$ & 35 & 68,6 & 2 & 28,6 & 37 & 63,8 & \\
\hline $31-45$ & 12 & 23,5 & 2 & 28,6 & 14 & 24,1 & \\
\hline Total & 51 & 100 & 7 & 100 & 58 & 100 & \\
\hline \multicolumn{7}{|l|}{ Pendidikan } & \multirow{5}{*}{0,274} \\
\hline Dasar (SD) & 5 & 9,8 & 2 & 28,6 & 7 & 12,1 & \\
\hline Menengah & 42 & 82,4 & 4 & 57,1 & 46 & 79,3 & \\
\hline (SLTP, SLTA) & 4 & 7,8 & 1 & 14,4 & 5 & 8,6 & \\
\hline \multicolumn{7}{|l|}{ Tinggi (S1) } & \\
\hline Total & 51 & 100 & 7 & 100 & 58 & 100 & \\
\hline \multicolumn{7}{|l|}{ Pekerjaan } & \multirow{4}{*}{0,325} \\
\hline IRT & 22 & 43,1 & 1 & 4,3 & 23 & 39,7 & \\
\hline PNS & 8 & 15,7 & 2 & 28,6 & 10 & 17,2 & \\
\hline Swasta & 21 & 41,2 & 4 & 57,1 & 25 & 43,1 & \\
\hline Total & 15 & 100 & 7 & 100 & 58 & 100 & \\
\hline \multicolumn{7}{|l|}{ Parietas } & \multirow{4}{*}{0,224} \\
\hline Parietas 1 & 13 & 25,5 & 1 & 24,1 & 14 & 24,1 & \\
\hline Parietas 2 & 30 & 58,8 & 3 & 42,9 & 33 & 56,9 & \\
\hline Parietas 3 & 8 & 15,7 & 3 & 42,9 & 11 & 19 & \\
\hline Total & 51 & 100 & 7 & 100 & 58 & 100 & \\
\hline \multicolumn{7}{|l|}{ Pengetahuan } & \multirow{3}{*}{0,147} \\
\hline Baik & 42 & 82,4 & 4 & 57,1 & 46 & 79,3 & \\
\hline Kurang & 9 & 17,6 & 3 & 42,9 & 12 & 20,7 & \\
\hline Total & 51 & 100 & 7 & 100 & 58 & 100 & \\
\hline
\end{tabular}
bahwa :

Dari tabel diatas dapat diketahui

1) Hasil analisis menunjukkan bahwa dari 7 
responden umur $<20$ tahun, 4 responden $(7,8 \%)$ mempunyai self efficacy baik dan 3 responden (42,9\%) mempunyai self efficacy kurang. Dari 37 responden umur 20-30 tahun, 35 responden $(68,6 \%)$ mempunyai self efficacy baik dan 2 responden $(28,6 \%)$ mempunyai self efficacy kurang. Dari 14 responden umur 31-45 tahun, 12 responden $(23,5 \%)$ mempunyai self efficacy baik dan 2 responden $(28,6 \%)$ mempunyai self efficacy kurang. Hasil uji chi-square menunjukkan nilai $\mathrm{p}=0,20>\alpha 0,05$ artinya tidak ada hubungan yang bermakna antara umur ibu dengan self efficacy ibu menyusui dalam memberikan ASI ekslusif pada bayi di RS Dr.Sobirin Kab. Musi Rawas Tahun 2018.

2) Hasil analisis menunjukkan bahwa dari 7 responden yang berpendidikan dasar (SD), 5 responden $(9,8 \%)$ memiliki self efficacy baik dan 2 responden $(28,6 \%)$ memiliki self efficacy kurang. Dari 46 responden yang berpendidikan menengah (SLTP,SLTA), 42 responden (82,4\%) memiliki self efficacy baik dan 4 responden $(7,8 \%)$ memiliki self efficacy kurang. Dari 5 responden yang berpendidikan tinggi (S1), 4 responden $(7,8 \%)$ memiliki self efficacy baik dan 1 responden $(14,4 \%)$ memiliki self efficacy kurang. Hasil uji chi-square menunjukkan nilai $\mathrm{p}=0,274>\alpha 0,05$ artinya tidak ada hubungan yang bermakna antara pendidikan ibu dengan self efficacy ibu menyusui dalam memberikan ASI ekslusif pada bayi di RS Dr.Sobirin Kab. Musi Rawas Tahun 2018.

3) Hasil analisis menunjukkan bahwa dari 23 responden dengan pekerjaan IRT, 22 responden $(43,1 \%)$ memiliki self efficacy baik dan 1 responden $(4,3)$ memiliki self efficacy kurang. Dari 10 responden dengan pekerjaan PNS, 8 responden $(15,7 \%)$ memiliki self efficacy baik dan 2 responden $(28,6 \%)$ memiliki self efficacy kurang. Dari 25 responden dengan pekerjaan swasta, 21 responden $(41,2 \%)$ memiliki self efficacy baik dan 4 responden $(57,1 \%)$ memiliki self efficacy kurang. Hasil uji chi-square menunjukkan nilai $\mathrm{p}=0,325>\alpha 0,05$ artinya tidak ada hubungan yang bermakna antara pekerjaan ibu dengan self efficacy ibu menyusui dalam memberikan ASI ekslusif pada bayi di RS Dr.Sobirin Kab. Musi Rawas Tahun 2018.

4) Hasil analisis menunjukkan bahwa dari 14 responden dengan pareitas 1, 13 responden $(25,5 \%)$ memiliki self efficacy baik dan 1 responden $(24,1 \%)$ memiliki self efficacy kurang. Dari 33 responden dengan parietas 2,30 responden $(58,8 \%)$ memiliki self efficacy baik dan 3 responden $(42,9 \%)$ memiliki self efficacy kurang. Dari 11 responden dengan parietas 3, 8 responden $(15,7 \%)$ memiliki self efficacy baik dan 3 responden (42,9\%) memiliki self efficacy kurang. Hasil uji chi-square menunjukkan nilai $\mathrm{p}$ $=0,224>\alpha 0,05$ artinya tidak ada hubungan yang bermakna antara parietas ibu dengan self efficacy ibu menyusui dalam memberikan ASI ekslusif pada bayi di RS Dr.Sobirin Kab. Musi Rawas Tahun 2018.

5) Hasil analisis menunjukkan bahwa dari 46 responden dengan pengetahuan baik, 42 responden $(82,4 \%)$ memiliki self efficacy baik dan 4 responden $(57,1 \%)$ memiliki self efficacy kurang. Dari 12 responden dengan pengetahuan kurang, 9 responden (17,6\%) memiliki self efficacy baik dan 3 responden $(42,9 \%)$ memiliki self efficacy kurang. Hasil uji chi-square menunjukkan nilai $\mathrm{p}=0,147>\alpha 0,05$ artinya tidak ada hubungan yang bermakna antara pengetahuan ibu dengan self efficacy ibu menyusui dalam memberikan ASI ekslusif pada bayi di RS Dr.Sobirin Kab. Musi Rawas Tahun 2018.

Tabel 5. Hasil Uji Hubungan Antara Variabel Dukungan Suami Dengan Self Efficacy 


\begin{tabular}{|c|c|c|c|c|c|c|}
\hline \multirow{3}{*}{$\begin{array}{c}\text { Dukungan } \\
\text { Suami }\end{array}$} & \multicolumn{4}{|c|}{ Self Efficacy } & \multirow{2}{*}{ Jumlah } & \multirow{3}{*}{$\boldsymbol{P}$} \\
\hline & \multicolumn{2}{|c|}{ Baik } & \multicolumn{2}{|c|}{ Kurang } & & \\
\hline & $\mathbf{n}$ & $\%$ & $\mathbf{n}$ & $\%$ & n $\%$ & \\
\hline Baik & 35 & 68,6 & 6 & 85,7 & 4170,7 & \multirow{2}{*}{0,661} \\
\hline Kurang & 16 & 31,4 & 1 & 14,3 & 1729,3 & \\
\hline Total & 51 & 100 & 7 & 100 & $58 \quad 100$ & \\
\hline
\end{tabular}

Hasil analisis menunjukkan bahwa dari 41 responden dengan dukungan suami baik, 35 responden $(68,6 \%)$ memiliki self efficacy baik dan 6 responden $(85,7 \%)$ mempunyai self efficacy kurang. Dari 17 responden $(31,4 \%)$ dengan dukungan suami kurang, 16 responden $(31,4 \%)$ memiliki self efficacy baik dan 1 responden (14,3\%) memiliki self efficacy kurang. Hasil uji chisquare menunjukkan nilai $\mathrm{p}=0,661>\alpha 0,05$ artinya tidak ada hubungan yang bermakna antara dukungan suami dengan self efficacy ibu menyusui dalam memberikan ASI ekslusif pada bayi di RS Dr.Sobirin Kab. Musi Rawas Tahun 2018.

\section{PEMBAHASAN}

Berdasarkan hasil uji statistik menggunakan uji chi square hubungan antara umur dengan self efficacy didapat $\mathrm{p}=0,20$. Dari hasil tersebut dapat disimpulkan bahwa tidak ada hubungan antara umur ibu dengan self efficacy ibu menyusui. Hal ini sejalan dengan hasil penelitian sebelumnya yang dilakukan oleh Fadhilah (2016) tentang analisis faktor yang berhubungan dengan self efficacy Ibu nifas dalam memberikan ASI ekslusif di Wilayah Kerja Puskesmas Tanah Kalikedinding Surabaya dengan nilai $p=0,33$.

Berdasarkan hasil uji statistik menggunakan uji chi square hubungan antara pendidikan dengan self efficacy didapat $p=$ 0,274 . Dari hasil tersebut dapat disimpulkan bahwa tidak ada hubungan antara pendidikan ibu dengan self efficacy ibu menyusui. Hal ini tidak sejalan dengan hasil penelitian sebelumnya yang dilakukan oleh Fadhilah (2016) tentang analisis faktor yang berhubungan dengan self efficacy Ibu nifas dalam memberikan ASI ekslusif di Wilayah Kerja Puskesmas Tanah Kalikedinding
Surabaya dengan nilai $\mathrm{p}=0,013$.

Berdasarkan hasil uji statistik menggunakan uji chi square hubungan antara pekerjaan dengan self efficacy didapat $\mathrm{p}=$ 0,325. Dari hasil tersebut dapat disimpulkan bahwa tidak ada hubungan antara pekerjaan ibu dengan self efficacy ibu menyusui. Hal ini sejalan dengan hasil penelitian sebelumnya yang dilakukan oleh Fadhilah (2016) tentang analisis faktor yang berhubungan dengan self efficacy Ibu nifas dalam memberikan ASI ekslusif di Wilayah Kerja Puskesmas Tanah Kalikedinding Surabaya dengan nilai $\mathrm{p}=0,226$.

\section{KESIMPULAN}

Berdasarkan hasil penelitian tentang hubungan karakteristik, tingkat pengetahuan dan dukungan suami dengan self efficacy menyusui dalam memberikan ASI ekslusif pada bayi di Rumah Sakit Dr. Sobirin Kabupaten Musi Rawas Tahun 2018 dapat disimpulkan :

1. Lebih dari sebagian responden berumur 20-30 tahun, lebih dari sebagian responden berpendidikan menengah (SLTP,SLTA), sebagian kecil dari responden dengan pekerjaan IRT, lebih dari sebagian responden dengan parietas 2 dan sebagian besar dari responden memiliki tingkat pengetahuan baik di Rumah Sakit Dr. Sobirin Kab. Musi Rawas Tahun 2018.

2. Lebih dari sebagian responden dengan dukungan suami baik di Rumah Sakit Dr. Sobirin Kab. Musi Rawas Tahun 2018.

3. Sebagian besar dari responden memiliki self efficacy baik di Rumah Sakit Dr. Sobirin Kab. Musi Rawas Tahun 2018.

4. Tidak ada hubungan antara umur ibu dengan self efficacy menyusui, tidak ada hubungan antara pendidikan ibu dengan self efficacy menyusui, tidak ada hubungan antara pekerjaan ibu dengan self efficacy menyusui, tidak ada hubungan antara parietas ibu dengan self efficacy menyusui, tidak ada hubungan 
antara tingkat pengetahuan ibu dengan self efficacy menyusui di Rumah Sakit Dr. Sobirin Kab. Musi Rawas Tahun 2018.

5. Tidak ada hubungan antara dukungan suami dengan self efficacy menyusui di Rumah Sakit Dr. Sobirin Kab. Musi Rawas Tahun 2018.

\section{SARAN}

1. RS Dr. Sobirin

Hasil penelitian ini diharapkan dapat menjadi masukan bagi Rumah Sakit dalam meningkatkan gerakan Rumah Sakit Sayang Ibu Bayi (RSSIB), sehingga program Inisiasi Menyusui Dini dapat terlaksana dengan baik.

2. Bagi Universitas Dehasen Program Studi Ilmu Keperawatan (S1)

Sebagai pedoman, bahan bacaan dan menambah khasanah bagi mahasiswa sehingga dapat memahami tentang Self Efficacy menyusui dalam memberikan ASI ekslusif. Serta dapat dijadikan sebagai bahan kepustakaan untuk penelitian selanjutnya yang terkait dengan penelitian tentang hubungan karakteristik, tingkat pengetahuan dan dukungan suami dengan self efficacy menyusui dalam memberikan ASI ekslusif pada bayi

3. Bagi Peneliti Selanjutnya

Peneliti selanjutnya agar dapat menggunakan desain yang berbeda yang lebih tepat untuk mengetahui hubungan karakteristik, tingkat pengetahuan dan dukungan suami dengan self efficacy menyusui dalam memberikan ASI ekslusif dengan menambah jumlah sampel dan menggunakan beberapa rumah sakit sebagai tempat penelitian agar dapat menunjukkan hasil yang lebih baik. Peneliti dapat meneliti faktor-faktor lain yang berhubungan dengan self efficacy seperti motivasi, pengalaman menyusui sebelumnya dan lain-lain.

\section{DAFTAR PUSTAKA}

Arikunto, S. 2014. Prosedur Penelitian Suatu Pendekatan Praktek, Jakarta: Rineka Cipta

Budiharto, 2006. Metodologi Penelitian Kesehatan, Jakarta: EGC

Mulyati, S \& Waluyanti, FT. 2013. Gambaran Self Efficacy Menyusui Pada Ibu Postpartum Dalam Memberikan ASI Ekslusif Pada Bayi di RS Medistra, Skripsi, Jakarta: Fakultas Ilmu Keperawatan UI 